The main violence occurrence place against infant was home. Home and public residential institution were the main VAC occurrence places for 1-4 years old children, and school was the main place of violence against the children over 5 years old.

Conclusions The declining death rate of VAC may be related to the social benign development. The related child protection laws and regulations should be implemented further and the prevention programs targeting the domestic violence and the school violence should be prioritised.

\section{ADVERSE CHILDHOOD EXPERIENCES STUDY AMONG UNIVERSITY STUDENTS IN TURKEY}

${ }^{1}$ Betul Ulukol, ${ }^{2}$ Akfer Kahilogullarl, ${ }^{3}$ Dinesh Sethi, ${ }^{4}$ Sevtap Velipasaoglu Guney, ${ }^{1}$ Ozdecan Bezirci Odek, ${ }^{5}$ Suvat Parin, ${ }^{6}$ Murat Yopbas, ${ }^{7}$ Sadik Aksit, ${ }^{7}$ Feyza Umay Koc, ${ }^{1}$ Kenan Kose, ${ }^{6}$ Gamze Can. ${ }^{1}$ Ankara University, Turkey; ${ }^{2}$ DIskapı Yildirim Beyazit Resarch Hospital, Turkey; ${ }^{3}$ World Health Organisation; ${ }^{4}$ Akdeniz University, Turkey; ${ }^{5}$ Yuzuncu Yil University, Turkey; ${ }^{6}$ Karadeniz Technical University, Turkey; ${ }^{7}$ Ege University, Turkey

\subsection{6/injuryprev-2016-042156.470}

Background There is a salient relationship between exposure to childhood traumatic events and negative health behaviours, and health status. The aim of this study was to identify the prevalence of adverse childhood experiences (ACEs) in a group of university students in Turkey and to evaluate the association of ACEs, with some health consequences including health risk behaviours.

Methods This is a descriptive cross-sectional study. 2257 students of 5 universities in Turkey were enrolled into the study between the years 2012-2013. A questionnaire modified from the ACE Questionnaire developed by CDC and Kaiser Permanente was used in the study. The questionnaire includes 53 questions on sociodemographic characteristics, household dysfunction, childhood maltreatment, health risk behaviours, somatic complaints and health status.

Results $47.9 \%$ of the 2257 respondents were male and $52.1 \%$ were female. The mean age of respondents was 20.1 years. The overall prevalence of childhood physical abuse, sexual abuse, emotional abuse, emotional neglect and physical neglect was $21.1 \%$, $7.9 \%, 9.8 \%, 8.8 \%$ and $5.7 \%$ respectively. $5.2 \%$ of respondents had divorced or separated parents. The overall prevalence of depression or suicide attempt, problem alcohol use, history of street drug use and involvement in crime or imprisonment in household members was $9.3 \%, 6.4 \%, 3.4 \%$ and $10.3 \%$ respectively. The ACE scores indicate that half of all respondents had a history of at least one ACE. ACE score was positively associated with health risk behaviours. The risk of smoking, harmful alcohol using and drug using increases dependently on the ACE score. Some health problems particularly emotional problems were associated with ACE score of the participants.

Conclusions This study suggests that ACE prevalence, health risk behaviours and certain health problems are high in a group of young adults in Turkey. The data from this study does not only provide information about the magnitude of the problem but also evidence that underlines the need to prioritise child maltreatment besides.

\section{THE FAMILY HEALTH, FUNCTIONING AND CHILD MALTREATMENT RISK OF FAMILIES EXPECTING A BABY}

\footnotetext{
1,2Eija Paavilainen, ${ }^{3}$ Sari Lepistö, ${ }^{1,3}$ Mika Helminen, ${ }^{1}$ Noora Ellonen. ${ }^{1}$ University of Tampere, Finland; ${ }^{2}$ Etelä-Pohjanmaa Hospital District, Finland; ${ }^{3}$ Pirkanmaa Hospital District, Finland
}

Background The purpose of this study is to describe the family health, functioning, social support and the child maltreatment risk and associations between them in families expecting a baby. It is crucial for welfare of children, to find families needing special support before the pattern of maltreatment has been developed within the family.

Methods The child maltreatment risk in families was measured using the Child Abuse Potential Scale (CAP). Health, functioning and social support were measured using the Family Health, Functioning and Social Support Scale (FAFHES). Data were collected from mothers and spouses at 30 weeks of pregnancy. Data were analysed by multivariate logistic modelling for explaining the child maltreatment risk level of families and for examining the associations between health, functioning, social support and the risk level.

Results Data included 380 families, 136 of them were expecting their first baby and 78 families had an increased risk for child maltreatment. Heightened risk was associated with the age of the spouse, the mother's education, the mental health problems of the spouse's father, the mother's concern about her spouse's drinking, and the mother's difficulties in talking about the family's problems. Child maltreatment risk was associated with family functioning and health. Families with risk received a little less support from maternity clinics.

Conclusions Families with child maltreatment risk and related factors were found. This knowledge can be applied for supporting families both during pregnancy and after the baby is born. The research continues as a part of Family Violence Research Project, by assessing the possible changes in family situation, while the baby is about 12 months of age.

\section{EFFECT OF SIBLINGS IN A BELGIAN SURVEILLANCE SYSTEM OF CHILD MALTREATMENT: COMPARISONS OF SEVERAL STATISTICAL METHODS}

${ }^{1}$ Christelle Senterre, ${ }^{1}$ Alain Levêque, ${ }^{2}$ Brigitte Vanthournout, 'Michèle Dramaix. ${ }^{1}$ Université Libre De Bruxelles, School of Public Health, Research Centre in Epidemiology, Biostatistics and Clinical Research, Belgium; '2SOS Enfants ULB, CHU Saint Pierre, Belgium

\subsection{6/injuryprev-2016-042156.472}

Background Over time, the circumstances encountered in case of child maltreatment, can be quite complex and then, can lead to methodological questions for the analysis of the data. Based on data coming from 395 children hospitalised, alone $(66.1 \%)$ or in siblings (33.9\%), in a paediatric ward between 2007 and 2012 for mistreatment or because of a severe risk of mistreatment, the aims of this study were to quantify the degree of similarity between sibling members, to study the differences between children hospitalised alone or with siblings and to compare four statistical methods for the analyses of the associated factors of mistreatment.

Methods To quantify the degree of similarity between sibship members, the Snijders and Bosker intracluster correlation coefficient was calculated and the statistical methods used were the logistic regression and GEE, both without and with robust standard error.

Results Almost all intracluster correlation coefficients were large, meaning that the sibling's members have a higher degree of similarity between them. The odds ratios were not exactly the same between the two models and the robust standard errors where almost always higher than the model-based standard errors in both logistic and GEE models leading to wider confidence intervals. 